\title{
OPTIMIZATION APPLIED TO ENERGY EFFICIENCY AND THERMAL COMFORT OF BUILDINGS: BIBLIOMETRIC ANALYSIS ON TECHNIQUES AND APPLICATIONS
}

\author{
C. F. da Silva ${ }^{a}$, \\ R. Z. Freire ${ }^{a}$, \\ and N. Mendes ${ }^{\mathrm{b}}$ \\ ${ }^{a}$ Pontifícia Universidade Católica do Paraná \\ (PUCPR), Escola Politécnica (EP) \\ Rua Imaculada Conceição, 1155 \\ CEP. 80215-901, Curitiba, Paraná, Brasil \\ cassiana.fagundes@pucpr.edu.br \\ ${ }^{a}$ Programa de Pós-Graduação em Engenharia \\ de Produção e Sistemas (PPGEPS) \\ ${ }^{\text {b} P r o g r a m a ~ d e ~ P o ́ s-G r a d u a c ̧ a ̃ o ~ e m ~ E n g e n h a r i a ~}$ \\ Mecânica (PPGEM) \\ Laboratório de Sistemas Térmicos (LST) \\ Received:May 31, 2018 \\ Revised: July 02, 2018 \\ Accepted: August 07, 2018

\section{NOMENCLATURE} \\ IF impact factor \\ Q1 the top 25\% of the IF distribution \\ Q2 middle-high position \\ Q3 middle-low position \\ Q4 the lowest position
}

\section{ABSTRACT}

The world's energy demand has raised concerns about supply difficulties, depletion of natural resources and environmental impacts such as destruction of ozone layer, global warming, climate change, among others. Recent studies indicate that energy consumption in buildings represents more than $40 \%$ of the world's energy consumption, with more than half of that attributed to air conditioning systems. Specific regulations and control strategies for heating, ventilation and air-conditioning (HVAC) systems should provide acceptable thermal comfort and reasonable indoor air quality. The evolution of researches in these areas can be evaluated by the organization of scientific production up to now. The objective of this study is to analyze quantitatively what was produced in terms of optimization associated to both energy savings and thermal comfort in buildings. This bibliometric analysis, based on Science Direct and IEEE Xplore databases, correlates common adopted terms to quantify how optimization, especially those associated to computational intelligence, are influencing building projects where thermal comfort and energy saving are taken into account. This research assumes a sample of 76 articles, and provided a statistical evaluation considering authors identification, and both articles and journals that were more cited by researchers in this area.

Keywords: bibliometric analysis; buildings; energy savings; thermal comfort

\section{INTRODUCTION}

Efforts to reduce the energy consumption associated with both use and design of buildings have direct relation to energy efficiency policies created by many governments. Most of these efforts are focused on heating, ventilation, and air conditioning (HVAC) systems that are receiving great attention from both scientific and industrial areas.

In the HVAC context, it is necessary not only to reduce energy consumption but also to guarantee indoor air quality and thermal comfort for the occupants. The majority of HVAC systems available in the market are just based on temperature regulation (Hao et al., 2014) and do not take into account additional variables that can be used to optimize thermal comfort and to avoid energy waste, e.g. the relative humidity.

In Freire et al. (2008), the authors propose an advanced control strategy for reducing energy consumption and maintaining the indoor conditions in an acceptable thermal comfort range, minimizing the energy consumption. Similar research in this area can be found in (Acosta et al., 2016; Ahn et al., 2017; Hazyuk et al., 2014; Zhai and Soh, 2017). As alternative to optimize thermal comfort in the building environment and to reduce energy demand, multiobjective optimization techniques, those that involve several parameters and control variables simultaneously, are been providing promising results.

Some works involving multiobjective optimization in buildings stand out (Ferreira et al., 2012; Khoroshiltseva et al., 2016; Morales-Valdés et al., 2014; Hamdy et al. 2011; Yang and Wang, 2012), among others.

Another way to work with several parameters that are related to thermal comfort and energy consumption is through the integration of multiobjective optimization and whole-building simulation. Some specific software capable to perform whole-building simulation are EnergyPlus (Crawley et al., 2001), WUFI®plus (Fraunhofer, 2010), Trnsys (Trnsys, 2010) and Domus software (Domus, 2013).

From this perspective, of associating building simulation and multiobjective optimization, the purpose of this work is to analyze the scientific development in parameters optimization focusing on thermal comfort and energy efficiency in buildings in a quantitative way, serving as base for a doctoral 
thesis. The methodological approach used is a systematic review of the specialized literature, this based on the bibliometric data collected from two databases Science Direct and IEEE Xplore. This two database have been chosen because they represent a considerable amount of journals relating those two previous mentioned areas: $i$ ) both thermal comfort and energy savings associated to buildings; and ii) parametric optimization.

This article is organized as follows. The next section specifies the methodology adopted in this study. A background of the literature on thermal comfort, energy efficiency and optimization areas is provided in the sequence. Results were presented in terms of most relevant authors and journals associated to the previous mentioned areas, and finally, conclusions and future works were addressed.

\section{METHODOLOGY}

This work initiates with the theoretical constitution of the research - background on thermal comfort, energy efficiency and metaheuristic optimization, starting by an explanation of the bibliometric analysis.

\section{Bibliometric - The Method}

Bibliometric research is a technique used to map the main authors, periodicals, and keywords of a given topic. In (Pilkington and Meredith, 2009), it is defined as a research technique that aims to analyze the size, growth, and distribution of the bibliography in a given field of knowledge.

In Ensslin et al. (2010), bibliometric research is described as a qualitative process of disclosure of statistical data, a set of articles, for the management of information and scientific knowledge of a given topic performed by means of a count of documents.

As presented in Araújo (2006), bibliometric was developed based on empirical laws on the behavior of literature. For this, it is necessary to know its three basic laws: Zipf's law that makes it possible to measure the frequency of occurrence of words; Lotka's law that deals with authors' productivity; and finally, Bradford's law, which highlights the productivity of journals (Bufrem and Prates, 2005).

In this context, the bibliometric laws adopt mathematical and statistical analysis of data to extract information and quantify the scientific publication on a certain theme.

\section{Sample Definition and Organization}

The sample of research works considered in this article comes from two international scientific databases: IEEE Xplore and Science Direct. IEEE Xplore is a database that indices both scientific and technical work published by the Institute of Electrical and Electronics Engineers (IEEE). Approximately 3 million full-text documents are available in more than 160 scientific journals, as well as 1,200 event annals and more than 3,800 technical standards. In the Science Direct database, the electronic publications of more than 1,800 journals from Elsevier and other scientific publishers with more than 10 million articles covering the most diverse areas of knowledge are available, such as the Sciences of Earth Sciences, Humanities and Literature and Arts, Health Sciences, Engineering, among others.

As mentioned before, the sample was defined from the two databases commented above. The identification of the keywords and the determination of the types of published documents were performed as shown in the flow chart presented in Fig. 1. The main idea in including the heuristic term was to consider the use of stochastic methods that already proved their efficiency in solving complex optimization problems.

\begin{tabular}{|c|c|c|}
\hline $\begin{array}{l}\text { Research: Science Direct } \\
\text { and IEEE Xplore } \\
\text { Keywords: } \\
\text { "Buildings" AND "Energy } \\
\text { Savings" AND "Thermal } \\
\text { Comfort" AND } \\
\text { "Optimization" AND } \\
\text { "Heuristic" }\end{array}$ & $\begin{array}{l}\text { Research areas: } \\
\text { Engineering Energy, } \\
\text { Environmental } \\
\text { Science, } \\
\text { Social Sciences, } \\
\text { Physical Sciences; }\end{array}$ & $\begin{array}{l}\text { Type of } \\
\text { Documents: } \\
\text { Joumals } \\
\text { (Only } \\
\text { ARTICLES) }\end{array}$ \\
\hline
\end{tabular}

Figure 1. Flowchart of the sample definition process defined in January 2017.

For the classification of the journals the impact factor (IF) was selected. This rank is available and presented by SCImago (SCImago, 2007) with quartile rankings, where Q1 or Q2 were selected for this research. Quartile rankings are associated to each journal according to categories divided by subjects of research. In this case, Q1 denotes the top $25 \%$ of the IF distribution, Q2 for middle-high position (between top 50\% and top 25\%), Q3 middle-low position (top $75 \%$ to top 50\%), and Q4 the lowest position (bottom $25 \%$ of the IF distribution).

Regarding the determination of publication type, considering books, patents, original research articles, reviews, annals of congresses, among others, it was decided to consider only peer-reviewed articles, since this type of publication generally precede books, and are considered relevant sources for research, and must present methodological rigor to be accepted for publication.

The composition of the sample was considered from 2006 to 2017 , due to the fact that it is desired to evaluate the last 11 years of researches in these areas. Initially, a total number of 108 articles was obtained, and after the refinement of the journals according to the SCImago criterium, a reduced sample of 93 articles were selected to be analyzed.

The bibliometric treatment of the articles is presented through a descriptive statistical analysis, obtained through illustrative tables and graphs generated using Microsoft Excel software. 


\section{BACKGROUND}

In the literature, several studies can be found associating thermal comfort, energy efficiency, and optimization applied to the buildings.

\section{Thermal Comfort}

For most of the international standards, as ISO 7730 (2005), ASHRAE55 (2005), and according to Fanger (1970), thermal comfort can be defined as "that condition of mind which expresses satisfaction with the thermal environment". The best-known thermal comfort index is the Fanger's Predicted Mean Vote (PMV) model, which combines four physical variables (air temperature, air velocity, mean radiant temperature, and relative humidity), and two personal variables (clothing insulation and activity level) into an index that can be used to predict the average thermal sensation of a large group of people.

In terms of thermal comfort measurements, the PMV is adopted specially when air conditioning systems are considered. It is an index that predicts the average value of a large group of people, according to a scale of thermal sensations based on 7 points (very hot, warm, slightly warm, neural, slightly cold, cold, very cold). It was created through statistical analyzes according to results obtained by Fanger (1970) in studies in Denmark considering climatized chambers. In his study, distinct hygrothermal conditions were considered for the indoor climate in the chamber, and people recorded their votes on the scale, selecting one option among the seven values commented before.

As there may be conflicts among users in relation to the thermal comfort of an environment, thermal comfort indices were developed to measure thermal comfort sensation in a given environment. Among other indices of comfort most disseminated in the literature, it can be mentioned the Effective Temperature (ET), and the Standard Effective Temperature (SET*).

The Effective Temperature can be defined as the dry bulb temperature index combination, (Moran and Shapiro, 2000) with barometric pressure, and air velocity in order to report thermal comfort sensation of a group of people occupying the interior of a certain environment. This ET concept was introduced in 1923 (Houghten and Yaglou, 1923). The SET* index was developed in order to design a set of standard conditions to be represented in common situations according to certain types of environments.

Through these definitions and criteria, it can be noticed that the thermal comfort sensation may vary from person to person in the same environment. In this way, one of the main difficulties of HVAC systems designers is how to attend to different profiles of people considering their preferences regarding the indoor climate conditions. As a solution to this problem, it is observed that analyzing only one variable to estimate thermal comfort is not the best solution.

One example where only one variable is considered was presented in Hamilton et al. (2001), where only temperature control is performed in the design of air conditioning systems. Most of these projects are due to the fact that temperature is one of the most relevant variables in estimating thermal comfort sensation (Trebien et al., 2007). However, when temperature is combined with relative humidity, reasonable levels of comfort can be reached when the control of these variables is properly performed (Mba et al., 2016). In the last decades, numerous researches were developed in order to evaluate thermal comfort of indoor environments, and for this reason, a large number of comfort models has been established considering distinct variables.

\section{Energy Efficiency}

Global energy consumption is growing rapidly (Quaschning, 2016), and concerns about supply difficulties, depletion of energy resources and environmental impacts are constantly in evidence. Buildings from commercial and residential sectors have a considerable contribution associated to the energy demand, reaching between $20 \%$ and $50 \%$ in developed countries, surpassing the large industrial and transport sectors (Pérez-Lombard et al., 2008; Peruzzi et al., 2014; Soares et al., 2013).

According to Dakwale et al. (2011), to achieve energy efficiency, it is necessary to raise awareness about energy consumption through training and education, to formulate patterns of energy consumption, to adopt an integrated approach by selecting the best option for energy generation in terms of cost and environmental impact, to use renewable energy sources, to modernize technology related to the generation of non-conventional energy, and finally to cancel subsidies for obsolete technology and subsidize modern technology.

Based on these concepts, it can be noticed the need for improvements of government regulations that standardizes and specifies practices associated to energy efficiency, especially those associated to buildings considering the reduction of environmental impacts and substantiality.

By analyzing the international context, several countries are already applying or promulgating laws, incentives or classification methods that promote the design and the construction of buildings with low environmental impact. As an example, the WordGBC Council was created in 2000, which consists of eight countries, the United States, Australia, Spain, United Kingdom, Japan, Russia, Canada and Arabia, whose mission is to accelerate the transformation of built environments in search of sustainability. In this way, labeling and its minimum criteria of energy efficiency, as described by Word Energy Council 
(2004), can be the high performance solutions in obtaining practical improvements.

In Brazil, PROCEL EDIFICA - National Program for Energy Efficiency in Buildings was instituted in 2003 by ELETROBRAS / PROCEL and works together with the Ministry of Mines and Energy, the Ministry of Cities, universities, research centers and entities in the governmental, technological, economic development, and civil construction areas. This program aims to raise awareness of the rational use of electricity in buildings, for this it provides actions to encourage and conserve the efficient use of natural resources, as water, ventilation and lighting, reducing environmental impacts and waste. Called Brazilian Labeling Program (PBE), it was developed to contribute to the rationalization of energy use, based on the energy efficiency of equipment and subsystems available in the market that are used in buildings.

In the last decades, several researches have been carried out in order to find methods that solve the challenge of finding optimal or quasi-optimal solutions of engineering problems associated to buildings' energy consumption and indoor thermal comfort.

\section{Optimization}

Optimization problems can be defined as the choice for the best element in a set of possible alternatives, through a specific objective function (such as maximization or minimization), that approaches or presents a desired value.

Alternatively, it is conceivable to enumerate all possible solutions and store the one that presents the best value for the objective function. However, for real and complex problems, this approach can be computationally impracticable due to the exponential growth of possible solutions as a function of the size of the problem.

More elaborate methods, which prioritize the speed in the search for the best possible solution related to a problem, known as metaheuristics, have been developed and used to solve practical optimization problems in engineering. The term metaheuristics was introduced by Glover (1986), it is characterized as problem solving methods that manage local search procedures with higher level strategies in order to create a process capable of escaping from local minimums by performing a robust search in a pre-defined solution space.

Since these procedures are specific to each metaheuristic, there is no guarantee that the obtained solution is the best possible solution for the problem. Several techniques can be used to solve optimization problems, where each one can provide best results according to its characteristics and the problem associated. Among well stablished techniques available, Genetic Algorithms (GA) (Goldberg,
1989), Tabu Search Algorithm (TSA) (Glover, 1986), Particle Swarm Optimization (PSO) (Kennedy and Eberhart, 1995), Ant Colony Optimization (ACO) (Dorigo and Stützle, 2004), Differential Evolution (DE) (Storn and Price, 1997), and Harmony Search (HS) (Geem et al., 2001), are some common strategies adopted to solve engineering problems, where most of them are based on evolution theory and natural behavior of species to explore the search space.

In the case of optimization applied to thermal comfort and energy savings in building, current studies generally pay more attention in the use of heating or cooling systems to improve internal thermal comfort (Freire et al., 2008; Freire et al., 2008). Focusing mainly on the resolution of the conflict between the energy consumption of the HVAC system and the internal climate condition emphasizing thermal comfort, most works do not consider how to use building elements to improve these conditions. In this context, the optimization of parameters such as shape, orientation, window-towall ratio (WWR), and internal space layout, can significantly influence thermal comfort and energy efficiency of buildings without significantly affect building project costs.

In Yu et al. (2015) a novel multi-featured new multiobjective optimization model that can assist designers of green buildings was presented. In this case, the Pareto solution was used to obtain a set of optimal solutions in building projects, where a multiobjective genetic algorithm (NSGA-II) was considered as theoretical basis for the multiobjective optimization. The NSGA-II algorithm optimized the design variables based on the prediction of energy consumption and thermal comfort in order to obtain the best possible solution. As a result, designers needed to limit the range of input variables and fully leverage the computer to compare different solutions.

In the work presented by Delgarm et al. (2016), a simulation-based multiobjective optimization of building energy efficiency and indoor thermal comfort was proposed to obtain optimized solutions based on distinct configurations for building envelopes. The optimization method was developed by integrating a multiobjective artificial bee colony (MOABC) technique implemented in MATLAB with EnergyPlus, which is a whole-building and energy simulation tool. The proposed optimization approach was applied to a single office room, where the building parameters included as decision variables were the room orientation, window size, cooling and heating temperature setpoints, glazing and wall material properties.

In the article presented by Kim et al. (2016), the objective was to optimize ecological systems. By considering thermal comfort and energy consumption of an educational establishment, optimal design scenarios were analyzed considering their economic and environmental effects. The study was conducted 
as follows: $i$ ) first, it was selected project variables and objective function were defined; ii) in the sequence, green systems optimization was performed; iii) after, comparative analysis of standard and optimal designs were evaluated; iv) finally, both economic and environmental evaluation of the project scenarios were performed. In order to compare the thermal comfort of the green systems with that of the existing building, this study used the percentage of dissatisfied predicted (PPD) which is the thermal comfort index based on the Fanger's PMV model.

Other studies focused on the optimization of parameters in thermal comfort and energy efficiency are developed by (Wang et al., 2015; Horikiri et al., 2015; Ansione et al., 2016; Chen et al., 2016; Martínez-Molina et al., 2016; Chowdhury et al., 2016 and Nagarathinam et al., 2017).

\section{RESULTS}

The first descriptive analysis of the publications on the selected areas was directed for identifying trends of growth or decay of interests in studies considering energy efficiency, thermal comfort and optimization applied to buildings. By classifying the articles of the sample according to the year of publication, it was possible to establish the comparison presented in Fig. 2. The volume of publications presents a cyclical character with relevant volume peaks in publications starting from 2012 to 2017 for the Science Direct base, and in the years from 2012 to 2017 for the IEEE Xplore, with periods of lower volume prior this interval.

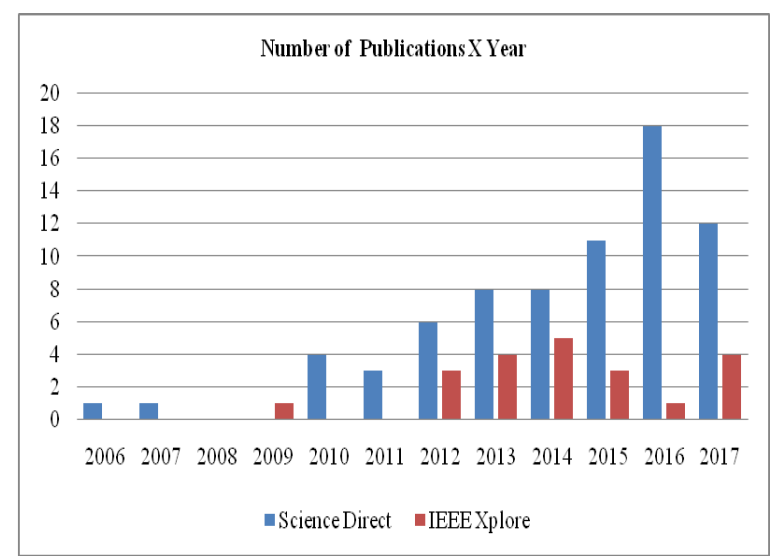

Figure 2. Evolution of publications over the last decade.

The second descriptive analysis has the objective of evaluating the dispersion of the research works during the analyzed period. In order to identify the main authors and periodicals in volume of publications, Figures 3 and 4 were presented to show the distribution of works in the selected areas according to authors, countries and journals, respectively.

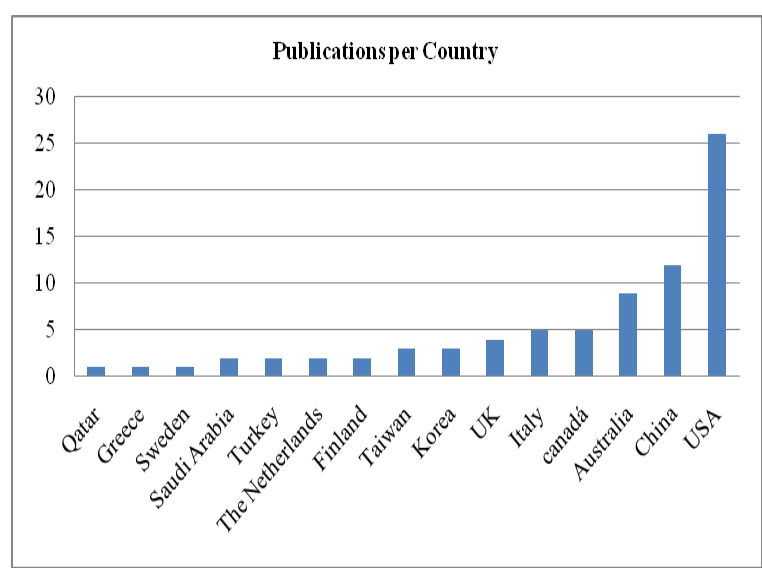

Figure 3. Sample distribution by country of origin.

By considering the distribution of works by author, the analysis of the sample revealed that the authors with the highest number of papers were Zhu Wang, Wang Lingfeng, Mohamed Hamdy, Ali Ghaharamani and Burcin Breick-Gerber, with 3 publications. Then, the other authors with 2 publications were Shengwei Wang, Rui Yang, Anastasios Dounis, Panagiota Karava, Ali Malkawi and Xiwang Li.

Regarding the distribution of articles by peerreviewed journals, it can be observed that Energy and Buildings with 27 publications is the most prominent periodical in volume (Fig. 4), as more than 25 articles was found in this journal between 2006 and 2017. Next, we highlighted Building and Environment and Applied Energy, with 10 and 6 publications, respectively. These publications represent $56 \%$ of the total sample and are concentrated mostly between 2015 and 2017 for the first journal, showing the recent interest by researchers in this area.

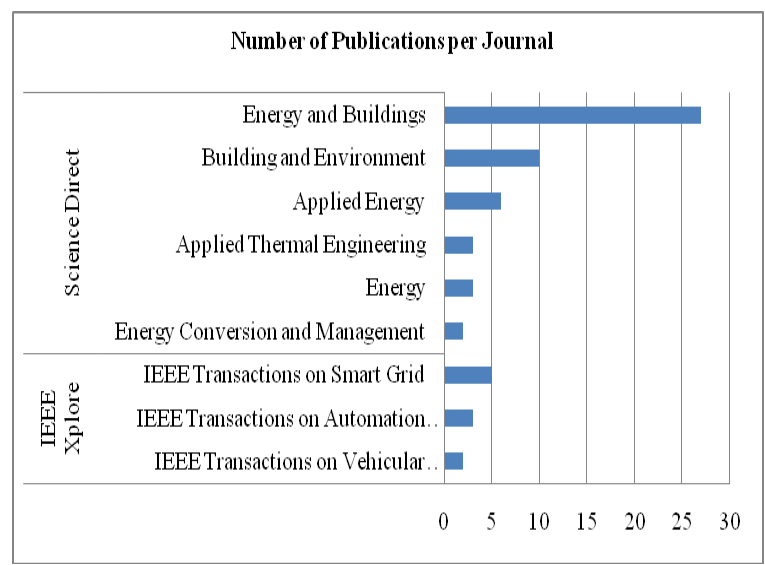

Figure 4. Comparison of the distribution of articles by the main journals.

The impact factor, the classification of the journal (best quartile), and the $\mathrm{H}$ index according to SCImago ranking of journals with highest number of publications in the two databases can be observed in Tab. 1. 
Table 1. Journals Impact Factor.

\begin{tabular}{lccc}
\hline \multicolumn{1}{c}{ Journal title } & SJR & $\begin{array}{c}\text { SJR Best } \\
\text { Quartile }\end{array}$ & $\begin{array}{c}\mathrm{H} \\
\text { index }\end{array}$ \\
\hline Energ. and Buildings & 2.073 & $\mathrm{Q} 1$ & 103 \\
\hline $\begin{array}{l}\text { Build. and } \\
\text { Environment }\end{array}$ & 2.121 & $\mathrm{Q} 1$ & 86 \\
\hline Appl. Energy & 2.998 & $\mathrm{Q} 1$ & 99 \\
\hline $\begin{array}{l}\text { IEEE Trans. Smart } \\
\text { Grid }\end{array}$ & 4.784 & $\mathrm{Q} 1$ & 66 \\
\hline Engineering & 1.832 & $\mathrm{Q} 1$ & 48 \\
\hline $\begin{array}{l}\text { IEEE Trans. Veh. } \\
\text { Technol. }\end{array}$ & 1.203 & $\mathrm{Q} 1$ & 116 \\
\hline
\end{tabular}

Additionally, for the IEEE database, some works were found in the IEEE Transactions on Vehicular Technology, even with no direct relationship with buildings. However, it can be observed that thermal comfort and energy efficiency are also a well stablished themes that are treated in the automotive sector.

Regarding the keywords of these publications, it can be observed in Fig. 5 that the keywords adopted in this research: build, energy consumption, optimization and HVAC were cited 14, 12, 11 and 10 times, respectively.

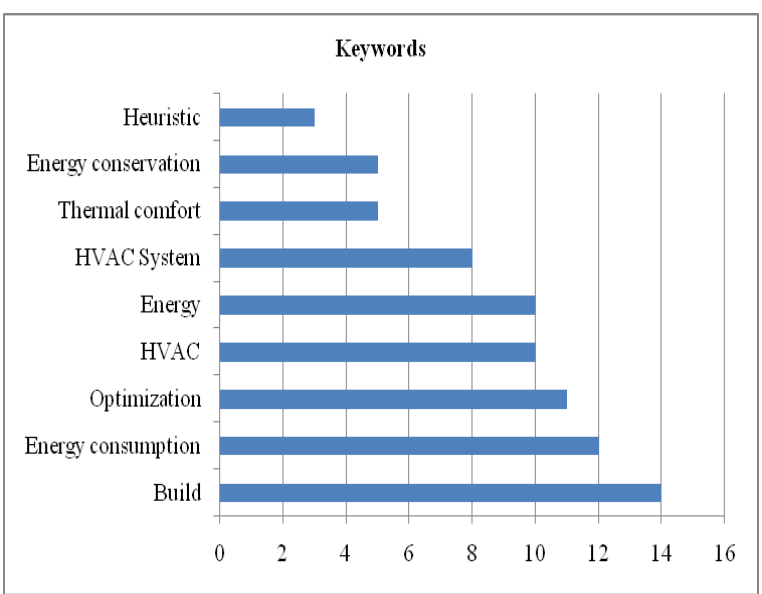

Figure 5. Keywords most cited in the sample.

\section{CONCLUSIONS}

The organization of data related to the scientific publication on energy savings, thermal comfort and optimization applied to buildings can contribute to the consolidation of the available knowledge and to the development of new visions and concepts. It is necessary, however, to show some limitations of the method and of the data sources that are available for the development of this work.

The platforms chosen for this research, IEEE Xplore and Science Direct, have predominance of both North American and English publications, not contemplating the academic production of many countries, especially those in development, that considered their native language. New keywords combinations will be performed with the objective of selecting Brazilian papers relevant to the study, that were not identified by the filter applied in the database.

Another limitation, originated in the sample process, concerns the type of the selected publications. Knowledge that has not been transformed into a scientific original research article has not been taken into account in this research. What is suggested in this case is the development of an investigation, whose sample consists of articles under evaluation and published in Brazil, although other vehicles of publication are not considered, but it is possible to identify authors and nuclei of Research with relevant contributions in the country.

Future works will focus on the construction of a network of relationships between existing publications and their co-citations. A systematic evaluation of the bibliography could be performed, classifying the works by optimization of parameters in thermal comfort, energy efficiency, thermal comfort, and also by energy efficiency in buildings.

\section{ACKNOWLEDGEMENTS}

Funding for this research was provided by grants from the Coordination for the Improvement of Higher Education Personnel (CAPES), and National Council for Scientific and Technological Development (CNPq) - grant number 304783/2017-0, and Pontifical Catholic University of Paraná - PUCPR, from Brazil.

\section{REFERENCES}

Acosta, A., González, A. I., Zamarreño, J. M, and Álvarez, V., 2016, Energy Savings and Guaranteed Thermal Comfort in Hotel Rooms through Nonlinear Model Predictive Controllers, Energy and Buildings, Vol. 129, pp. 59-68.

Ahn, J., and Cho, S., 2001, Development of an Intelligent Building Controller to Mitigate Indoor Thermal Dissatisfaction and Peak Energy Demands in a District Heating System, Building and Environment, Vol. 124, pp. 57-68.

Araújo, C., 2006, Bibliometria: evolução Histórica e Questões Atuais, Pesquisa Brasileira em Ciência da Informação e Biblioteconomia, Vol. 2, pp. 11-32. (in Portuguese)

Ascione, F., Bianco, N., Stasio, C., Mauro, G. M., and Vanoli, G. P., 2016, Simulation-Based Model Predictive Control by the Multi-Objective Optimization of Building Energy Performance and Thermal Comfort, Energy and Buildings, Vol. 111, pp. 131-144.

Ashare, 2005, Handbook of Fundamentals; Chap. 8 - Physiological Principles and Thermal Confort, American Society of Heating, Refrigerating and Air Conditioning Engineers, Atlanta, GA. 
Chen, X., Wang, Q., and Srebric, J., 2016, Occupant Feedback based Model Predictive Control for Thermal Comfort and Energy Optimization: a Chamber Experimental Evaluation, Applied Energy, Vol. 164, pp. 341-351.

Chowdhury, A. A., Rasul, M. G., and Khan, M. M. K., 2016, Chapter 7 - Parametric Analysis of Thermal Comfort and Energy Efficiency in Building in Subtropical Climate, Thermofluid Modeling for Energy Efficiency Applications, Academic Press, pp. 149-168.

Crawley, D. B., Lawrie, L. K., Winkelmann, F. C., Buhl, W. F., Huang, Y. J., Pedersen, C. P., Strand, R. K., Liesen, R. J., Fisher, D. E., Witte, M. J., and Glazer, J., 2001, EnergyPlus: creating a NewGeneration Building Energy Simulation Program, Energy and Buildings, Vol. 33, No. 4, pp. 319-331.

Dakwale, V., Ralegaonkar, R., and Mandavgan E., S., 2011, Improving Environmental Performance of Building Through Increased Energy Efficiency: a Review, Journal of Sustainable Cities and Society, Vol. 1, No. 4, pp. 211-218.

Delgarm, N., Sajadi, B., and Delgarm, S., 2016, Multi-Objective Optimization of Building Energy Performance and Indoor Thermal Comfort: a New Method Using Artificial Bee Colony (ABC), Energy and Buildings, Vol. 131, pp. 42-53.

Domus, 2013, Procel Edifica Programa de Simulação Higrotermoenergética de Edificações, Procel Edifica. (in Portuguese)

Dorigo, M., and Stützle, T., 2004, Ant Colony Optimization, Massachusetts Institute of Technology, Cambridge.

Ensslin, L., Ensslin, S. R., and Pinto, H. M., 2010, Processo de Análise Bibliométrica, Processo Técnico com Patente de Registro Pendente Junto ao INPI, Brasil. (in Portuguese)

Fanger, P. O., 1970, Thermal Confort, McGrawHill Inc., New York, USA.

Fanger, P. O., 1972, Thermal Comfort: analysis and Applications in Environmental Engineering, McGraw-Hill, New York, USA.

Ferreira, P. M., Ruano, A. E., Silva, S., and Conceição, E. Z. E., 2012, Neural Networks based Predictive Control for Thermal Comfort and Energy Savings in Public Buildings, Energy and Buildings, Vol. 55, pp. 238-251.

Fraunhofer IBP Holzkirchen, 2010, Overview of WUFI, Fraunhofer IBP.

Freire, R. Z., Oliveira, G. H. C., and Mendes, N., 2008, Predictive Controllers for Thermal Comfort Optimization and Energy Savings, Energy and Buildings, Vol. 40, No. 7, pp. 1353-1365.

Freire, R. Z., Oliveira, G. H., and Mendes, N., 2008, Development of Regression Equations for Predicting Energy and Hygrothermal Performance of Buildings, Energy and Buildings, Vol. 40, No. 5, pp. 810-820.

Freire, R. Z., Oliveira, G. H., and Mendes, N., 2008, Predictive Controllers for Thermal Comfort
Optimization and Energy Savings, Energy and Buildings, Vol. 40, No. 7, pp. 1353-1365.

Geem, Z. W., Kim, J. H., and Loganathan, G. V., 2001, A New Heuristic Optimization Algorithm: harmony Search, Simulation, Vol. 76, No. 2, pp. 6068.

Glover, F., 1986, Future Paths for Integer Programming and Links to Artificial Intelligence, Computers and Operations Research, Vol. 13, No. 5, pp. 533-549.

Golderg, D. E., 1989, Genetic Algorithms in Search, Optimization, and Machine Learning, Reading, MA: ADDISON Wesley.

Hamdy, M., Hasan, A., and Siren, K., 2011, Impact of Adaptive Thermal Comfort Criteria on Building Energy Use and Cooling Equipment Size Using a Multi-Objective Optimization Scheme, Energy and Buildings, Vol. 43, No. 9, pp. 2055-2067.

Hao, H., Lin, Y., Kowli, A. S., Barooah, P., and Meyn, S., 2014, Ancillary Service to the Grid Through Control of Fans in Commercial Building HVAC Systems, IEEE Transactions Smart Grid, Vol. 5, No. 4, pp. 2066-2074.

Hazyuk, I., Ghiaus, C., and Penhouet, D., 2014, Model Predictive Control of Thermal Comfort as a Benchmark for Controller Performance, Automation in Construction, Vol. 43, pp. 98-109.

Horikiri, K., Yao, Y., and Yao, J., 2015, Numerical Optimisation of Thermal Comfort Improvement for Indoor Environment with Occupants and Furniture, Energy and Buildings, Vol. 88, pp. 303-315.

Houghten, F. C., and Yaglou, C. P., 1923, Determining Lines of Equal Confort, Journal of the American Society of Heating and Ventilating Engineers, Vol. 29, pp. 165-176.

ISO 7730, 2005, Ergonomics of the Thermal Environment: Analytical Determination and Interpretation of Thermal Comfort Using Calculation of the PMV and PPD Indices and Local Thermal Comfort Criteria, International Organization Standardization, Genève.

Jevons, R., Carmichael, C., Crossley, A., and Bone, A., 2016, Minimum Indoor Temperature Threshold Recommendations for English Homes in Winter - A Systematic Review, Public Health, Vol. 136, pp. 4-12.

Kim, J., Hong, T., Jeong, J., Koo, C., and Jeong, K., 2016, An Optimization Model for Selecting the Optimal Green Systems by Considering the Thermal Comfort and Energy Consumption, Applied Energy, Vol. 169, pp. 682-695.

Kennedy, J., and Eberhart, R. C., 1995, Particle Swarm Optimization, in: Proceedings of IEEE International Conference on Neural Networks, Piscataway, NJ, USA, pp. 1942-1948.

Korkas, C. D., Baldi, S., Michailidis, I., and Kosmatopoulos, E. B., 2016, Occupancy-Based Demand Response and Thermal Comfort Optimization in Microgrids with Renewable Energy 
Sources and Energy Storage, Applied Energy, Vol. 163, pp. 93-104.

Khoroshiltseva, M., Slanzi, D., and Poli, I., 2016, A Pareto-Based Multi-Objective Optimization Algorithm to Design Energy-Efficient Shading Devices, Applied Energy, Vol. 184, No. 15, pp. 1400-1410.

Mba, L., Meukam, P., and Kemajou, A., 2016, Application of Artificial Neural Network for Predicting Hourly Indoor Air Temperature and Relative Humidity in Modern Building in Humid Region, Energy and Buildings, Vol. 121, pp. 32-42.

Martínez-Molina, A., Tort-Ausina, I., Cho, S., and Vivancos, J. S., 2016, Energy Efficiency and Thermal Comfort in Historic Buildings: a Review, Renewable and Sustainable Energy Reviews, Vol. 61, pp. 70-85.

Morales-Valdés, P., Flores-Tlacuahuac, A., and Zavala, V. M., 2014, Analyzing the Effects of Comfort Relaxation on Energy Demand Flexibility of Buildings: a Multi-Objective Optimization Approach, Energy and Buildings, Vol. 85, pp. 416-426.

Moran, M. J., and Shapiro, H. N., 2000, Fundamentals of Engineering Thermodynamics, 4th Edition, Jhon Wiley and Sons.

Nagarathinam, S., Doddi, H., Vasan, A., Sarangan, V., Ramakrishna, V. P., and Sivasubramaniam, A., 2017, Energy Efficient Thermal Comfort in Open-Plan Office Buildings, Energy and Buildings, Vol. 139, pp. 476-486.

Pérez-Lombard, L., Ortiz, J., and Pout, C., 2008, A Review on Buildings Energy Consumption Information, Energy and Buildings, Vol. 40, pp. 394398.

Peruzzi, L., Salata, F., Lieto Vollaro, A. de, and Lieto Vollaro, R. de, 2014, The Reliability of Technological Systems with High Energy Efficiency in Residential Buildings, Energy and Buildings, Vol. 68, pp. 19-24.

Pilkington, A., and Meredith, J., 2009, The Evolution of the Intellectual Structure of Operations Management - 1980 - 2006: a Citation/Co-Citation Analysis, Journal of Operations Management, Vol. 27, No. 3, pp.185-202.

Quaschning, V., 2016, Understanding Renewable Energy Systems, Routledge.

SCImago, 2007, SCImago Journal \& Country Rank Retrieved, SJR.

Storn, R., and Price, K., 1997, Differential Evolution - A Simple and Efficient Heuristic for Global Optimization over Continuous Spaces, Journal of Global Optimization, Vol. 11, pp. 341-359.

Soares, N., Costa, J. J., Gaspar, A. R, and Santos, P., 2013, Review of Passive PCM Latent Heat Thermal Energy Storage Systems Towards Buildings' Energy Efficiency, Energy and Buildings, Vol. 59, pp. 82-103.

Trebien, R., Mendes, N., and Oliveira, G. H. C., 2007, Sensibilidade do Índice PMV e Regiões de Conforto Visando Aperfeiçoamento de
Climatizadores, Ambiente Construído, Vol. 7, pp. 7187. (in Portuguese)

Trnsys, 2010, Trnsys 17 Documentation, Solar Energy Laboratory, UW-Madison.

Wang, Y., Kuckelkorn, J., Zhao, F., Liu, D., Kirschbaum, A., and Zhang, J., 2015, Evaluation on Classroom Thermal Comfort and Energy Performance of Passive School Building by Optimizing HVAC Control Systems, Building and Environment, Vol. 89, pp. 86-106.

World Energy Council, 2004, Energy Efficiency: a Worldwide Review - Indicators, Policies, Evaluation.

Wu, R., Mavromatidis, G., Orehounig, K., and Carmeliet, J., 2017, Multiobjective Optimisation of Energy Systems and Building Envelope Retrofit in a Residential Community, Applied Energy, Vol. 190, pp. 634-649.

Yang, R., and Wang, L., 2012, Multi-Objective Optimization for Decision-Making of Energy and Comfort Management in Building Automation and Control, Sustainable Cities and Society, Vol. 2, pp. 1-7.

Yu, W., Li, B., Jia, H., Zhang, M., and Wang, D., 2015, Application of Multi-Objective Genetic Algorithm to Optimize Energy Efficiency and Thermal Comfort in Building Design, Energy and Buildings, Vol. 88, pp. 135-143.

Zhai, D., and Soh, Y. C., 2017, Balancing Indoor Thermal Comfort and Energy Consumption of ACMV Systems Via Sparse Swarm Algorithms in Optimizations, Energy and Buildings, Vol. 149, pp. $1-15$.

Zhang, L., Gudmundsson, O., Thorsen, J. E., Li, H., Li, X., and Svendsen, S., 2016, Method for Reducing Excess Heat Supply Experienced in Typical Chinese District Heating Systems by Achieving Hydraulic Balance and Improving Indoor Air Temperature Control at the Building Level, Energy, Vol. 107, pp. 431-442. 